\title{
Cognitive Assessment Strategy Using Cmaptools Application with Rasch Modeling
}

\author{
Mobinta Kusuma ${ }^{1,{ }^{*}}$ Haryanto $^{2,}$ Ani Rusilowati ${ }^{3,}$ Lisdiana $^{3}$ \\ ${ }^{1}$ Postgraduate Student, Universitas Negeri Yogyakarta, Indonesia \\ ${ }^{2}$ Universitas Negeri Yogyakarta, Indonesia \\ ${ }^{3}$ Universitas Negeri Semarang, Indonesia \\ *Corresponding author. Email: mobintakusuma.2021@student.uny.ac.id, mobintakusuma@upstegal.ac.id
}

\begin{abstract}
This study aims to find a fit model instrument consisting of the validity and reliability of cognitive assessment using the campstool and the distribution of student achievement in making concept maps as a cognitive assessment strategy. As we know, the assessment of cognitive aspects is one way to assess student learning outcomes. Cognitive abilitiy is the basis of the development of students' thinking skill. One application that can be used to assess students' cognitive abilities is the CMAPTOOL concept map application developed by the Institute of Human and Machine Cognition (IHMC). The research method category is quantitative research. Students' cognitive abilities through the use of the CMAPTOOL application were then assessed using the concept map assessment indicators. The indicator assessment consist of 5 aspects including concept formation, principle formation, understanding concept linkage, problem solving and composing section. The type of concept map assessment used is a fill-in map scheme. The values obtained from the assessment of the concept map were analyzed through Rasch modelling. The results showed that the assessment tools with validity 0.69 and reliability of model 0.59 . The results of the mastery of students' cognitive abilities are categorized in mastery levels 1 to 4 . Cognitive assessment using CMAPTOOL can be used as strategy to assess student achievement.
\end{abstract}

Keywords: assessment, cmaptools, cognitive, Rasch modelling

\section{INTRODUCTION}

Learning is the focus and ultimate goal of the learner-centered paradigm. Because of this, assessment plays a key role in shifting to a learner-centered approach. When assessing students' learning, we force the questions, "What have our students learned and how well have they learned it?" "How successful have we been at what we are trying to accomplish?" Because of this focus on learning, higher education assessments are sometimes referred to as outcomes assessments or student outcomes assessments [1]. Teaching Effectiveness Program in Oregon University defines that assessment is the process of gathering and discussing information from a variety of sources to develop a deep understanding of what students know, understand, and can do with their knowledge as a result of their educational experiences; the process culminates when assessment results are used to improve further learning. The ability to evaluate one's own work accurately and constructively does not develop automatically. The more intellectually immature students are, the more likely their personal investment will be to refract what they see when they look at their own work [2].

The purpose of someone assessing learning can be defined to know about constructivist concept in the learning process. Various methods have been proposed to assess students' conceptual structure [3]. Constructing concepts will make students understand better in their study. It also can treat students in having meaningful learning. Meaningful learning can integrate new knowledge with existing knowledge and produce a stronger knowledge structure and correct misconception that may exist [4].

Concept maps are graphical representations of student's knowledge about a topic [5]. A concept map is pictorial essays, a method that describes the main concepts of a lesson from its points. They include supporting information that shows how student has organized his ideas. Good concept map force their creators to challenge their own understanding and build a solid foundation for further information. 
In making concept mapping there are three main components, namely key concepts, subordinate concepts and labels to form propositions. The definition of a proposition is defined as the relationship between two concepts connected by a labeled line. In this study, a concept map of the $\mathrm{S}$ model will be developed, where students are given a number of concepts with labels provided. Model $\mathrm{S}$ is a model that requires respondents to be able to make CMA based on a number of concepts with labels provided. This model can be used as an effective CMA assessment technique and is suitable for wide-scale assessments [6,7].

Concept map construction can be made using the help of the cmaptools application developed by Instute Human Machine Cognition (IHMC). Concept maps created with cmaptools can contain related concepts related to labels. The related concepts between the main concept and sub-concepts with labels are called prepositions [7]. Students can find out their thinking skills through the construction of related concepts arranged in a concept map. Concept maps were compiled by students using cmaptools and assessed for knowledge construction through prepositional constructions. The concept construction measurement strategy was carried out through the assessment of students' concept map results. This study aims to find a fit model instrument consisting of the validity and reliability of cognitive assessment using campstool and the distribution of student achievement in making concept maps as a cognitive assessment strategy.

\section{METHOD}

\subsection{Research Design}

Research design is quantitative research. The research was conducted in one of the high schools in the city of Semarang. The object of research in the form of an assessment of concept maps with research subjects are Senior High School students totaling 22 students. Data were collected using a concept map test which was assessed from the relationship between concepts by being connected by labels that became a single preposition. Research procedure refers to [15] explains as follows: (1) Determining the purpose of the assessment, (2) Design of the assessment, (3) Development of the instrument, (4) Testing of the instrument which includes expert review, (5) limited trial, (6) Assembly of the final instrument.

\subsection{Research Indicator}

The data is processed using Rasch modeling. Research achievement indicators are seen from the reliability and validity results above 0.6 through statistical summary instrument analysis and student ability analysis through person item map results. Test items used to measure construction ability using cmaptools totaling 22 test items. Instrument indicator consist of 5 aspects including concept formation, principle formation, comprehending of concept linkage, problem solving and composing part. Item validation using polytomous modeling called PCM modeling with three categories $(0,1$ and 2$)$ and also addition of achievement aspects of preposition linkage.

\section{FINDING AND DISCUSSION}

The objectives of the research were finding model fit instrument consist of validity and reliability of cognitive assessment using campstool and also levelling student achievement in making concept map as the cognitive assessment strategy. The fill in the map technique requires the subject to be able to make a concept mapping from the available concepts or labels into the form of a hierarchical diagram that has been provided [16]. Instrument validity content achieve value 3.87 from the mean of 4 rater. The results obtained from the test data and processed using Rasch modelling [8] show that the achievement of the statistical summary of the reliability values is shown in table 1 . This table shows that the reliability value is above 0.6 which indicates a valid and reliable test, however the results of the test item reliability measurement show a value below 0.6 which indicates the test item is quite reliable. The validity of the instrument is judged by the similarity between the concept mapping and the master map.

Table 1. Summary statistics validity and reliability

\begin{tabular}{|l|l|}
\hline Summary statistics & Values \\
\hline Validity Content & 3.87 \\
\hline Model Item Validity & 0.69 \\
\hline Real Person Reliability & 0.62 \\
\hline Model Person Reliability (KR-20) person & 0.64 \\
\hline $\begin{array}{l}\text { Cronbach Alpha } \\
\text { reliability }\end{array}$ & 0.64 \\
\hline Real Item Reliability & 0.56 \\
\hline Model Item Reliability & 0.59 \\
\hline
\end{tabular}

Reliability is a very important key to determine the consistency of the usability of the test, so that it can be used by class categories from lower to upper levels. The data on the characteristics of the items are shown by the Person DIF curve in Figure 1. The curve in Figure 1 shows the level of difficulty of the questions. The S17 code question is relatively more difficult than other questions, while the S21 code question is the easiest question for students to work on. The difficulty level of the S21 question is one of the causes of the low item reliability calculation compared to the person reliability as shown in Table 1. 


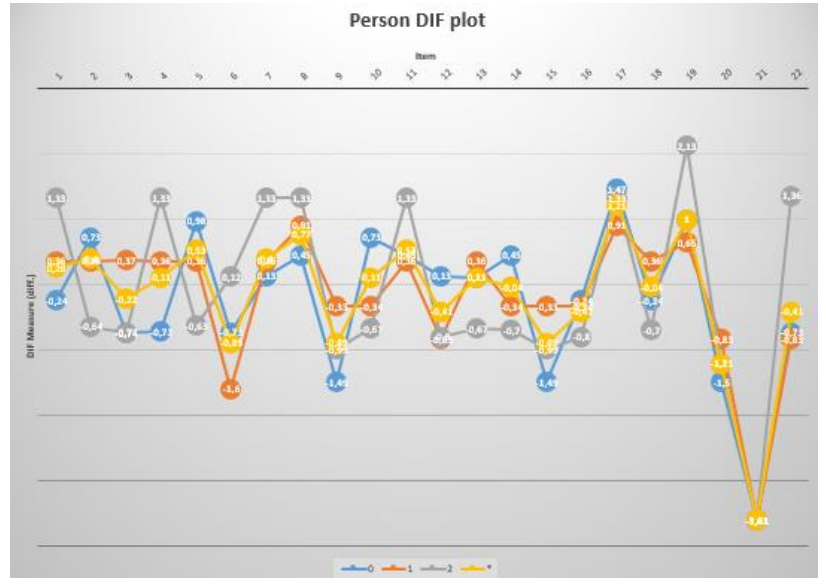

Figure 1. Person DIF Plot

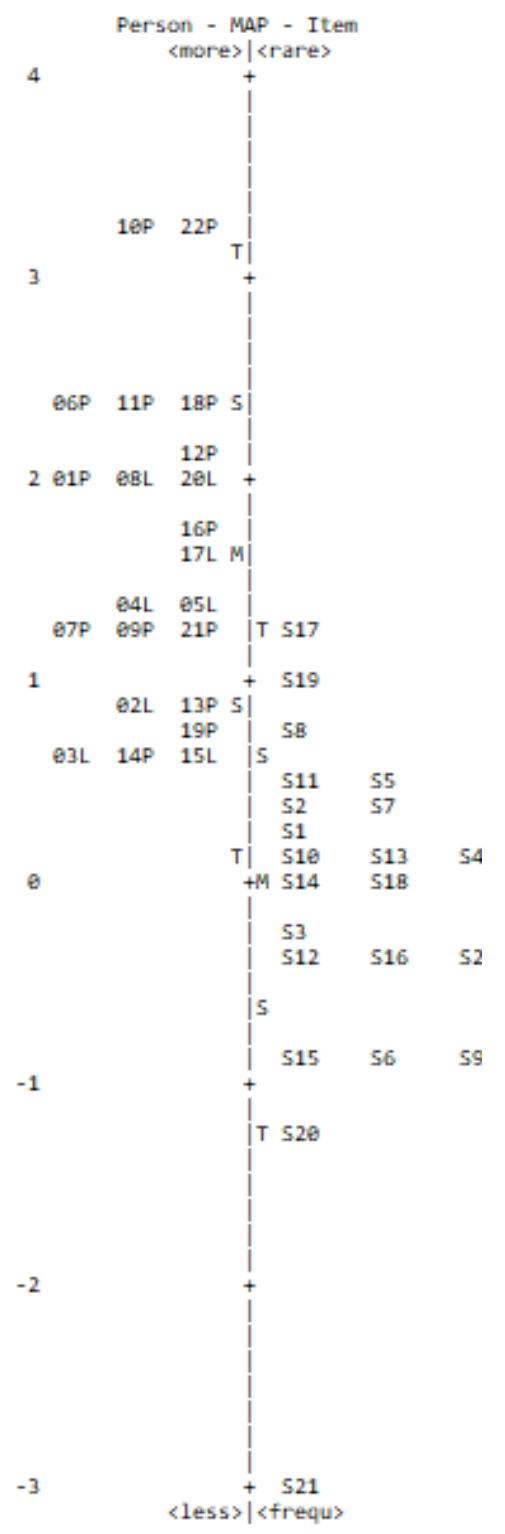

Figure 2. Person in Map Results

The data on the distribution of abilities and levels of difficulty are shown by analysis of the Wright Person in
Map shown in Figure 2. Wright's map analysis shows that the distribution of student abilities is on the left and the distribution of difficulty levels is on the right. First, on the map on the left it can be seen that as many as 13 students have a high level of ability, which is indicated by the ability to answer more difficult questions. Students with the highest abilities are 10P and 22P students, while students with low abilities are 03L, 14P, $15 \mathrm{~L}$. Students' abilities are low but in the ability to answer with a success rate of $81.18 \%$. Second, on the right side of Wright's map, the questions with the code S17 were ranked at the top for the category of difficult questions and the questions coded S21 were ranked the lowest as the categories for questions that were easy for students to work on. Students' abilities in the constructivist and understanding concept are influenced by the mastery of thinking skill. Concept mapping can be used to describing student constructivist concept. Knowing the final result and score of that concept mapping will be needed an assessment. Indirectly, the process of conceptual thinking by utilizing cmaptools, can make students able to construct concepts that have been previously owned with new concepts obtained so that they are able to process information into better and developing concepts. Conceptual constructive and understanding help the student for achieve the meaningful learning process. It also can make the student solve the learning problems intensively. Constructivism learning aims for students to be able to master concepts and their interrelationships, and be able to use scientific methods based on a scientific attitude to solve the problems they face, so that they are more aware of the greatness of God Almighty [9]. Students not only know and memorize concepts but can understand these concepts and make connections between one concept and another.

The ability to construct and understand concepts can be seen from the score for each concept classification. The type of score interpretation can be distinguished in 2 interpretation models:1. Norm-referenced score, comparing test results between students with one another; 2. Criterion-referenced score, comparing student test results with the achievement of the expected criteria or level $[10,11]$. In this study, the criterionreferenced score interpretation type was used, namely by comparing the scores obtained by students with the level of achievement of the expected criteria. In this method, the rater scores the correct proposition based on its comparison with the higher-level structure in the concept mapping. The total score is obtained by taking into account the hierarchical level, cross-links (crossrelationships), the number of correct propositions and the number of examples given. The hierarchical relationship score is 5 , each crosslink is scored 10 , each valid proposition is scored 1 and each given example is 
scored 2. Evaluation of the thinking process on the concept was observed by giving a rating scale as follows: Level 1 (poor), Level 2 (medium), Level 3 (good) and Level 4 (very good).

Concept map scoring is determined by 5 components. The concept map score is converted into the value of learning outcomes quantitatively according to the predetermined calculation formula. While the assessment of the concept thinking process is determined by five components, where each component has a weighted number that can be added up as a whole to determine the total score and level of the concept thinking process in students. The level assessment of the concept thinking process can be used as a qualitative assessment of students' ability to think concepts. The results showed that the average concept thinking process ability was at level IV with a very good category. Level IV describes the ability of conceptual thinking processes as follows: Concepts with related subconcepts $>75 \%$, Related concepts form logical sentences $>75 \%$, There are all labels $(100 \%)$ on the connecting line between concepts, All labels are appropriate as conjunctions ( $100 \%)$, Can relate concepts clearly and significantly $>75 \%$, Able to create/complete a comprehensive hierarchical structure and link between concepts( $>75 \%)$, Able to create crosslinks with the right label $>75 \%$, Examples provided are relevant and related $>75 \%$ concept, the concept map is legible and clear (>75\%), There are illustrations with more than 2 colors, the concept map is organized and neatly arranged. In social psychology, thinking is defined as the most important part that distinguishes humans from animals, plants and inanimate objects. Thoughts have powerful processes, though they may seem simple and weak, they are deeper and more powerful than one can imagine. Thinking is capable of producing knowledge, understanding, values, beliefs and principles [12]. Thinking can be defined as the process of generating new mental representations through information transformation involving complex interactions between mental attributes such as judgment, abstraction, reasoning, imagination, and problem solving [13]. The normal thinking process will include three main components as follows: First, thinking is a cognitive activity that occurs in a person's mental or mind, it is not visible, but can be concluded based on visible behavior. Second, thinking is a process that involves some manipulation of knowledge in the cognitive system. Knowledge that has been stored in memory is combined with current knowledge so as to change one's knowledge of the situation at hand [14].

\section{CONCLUSION}

The results of the validity and reliability test of the items as well as the students' ability to use concept maps met the statistical standards using Rasch modeling included in fit model category. The achievement of the assessment can use several levels of criteria from level 1 to level 4. The strategy for assessing thinking skills can be done using a concept map assisted by the cmaptool application. Cognitive assessment using cmaptool can be used as strategy to assess student achievement.

\section{AUTHORS' CONTRIBUTIONS}

MK contributed to the design of the assessment model, data collection and interpretation of the results. $\mathrm{BK}, \mathrm{AR}, \mathrm{L}$ and $\mathrm{H}$ are the supervisors of the research project. AR contributed in model supervision. L contributed in mastering content validation. $\mathrm{H}$ contributed in supervising data analysis.

\section{ACKNOWLEDGMENTS}

I would like to acknowledgment and give my warmest thanks to my supervisors who make this all projects is possible. His/Her guidance and advice carried through all the stage writing this project.

\section{REFERENCES}

[1] J.E. Freed, M.E. Huba, Learner-centered assessment on college campuses: Shifting the focus from teaching to learning. Allyn \& Bacon, 160 Gould St., Needham Heights, 2000, MA 02494.

[2] D. DeZure, Learner-centered teaching: Five key changes to practice. The Review of Higher Education, 2004, vol. 27(2), pp. 271-272.

[3] J.H. McMillan, Fundamental assessment principles for teachers and school administrators. Practical Assessment, Research, and Evaluation, 2000, vol. 7(1),p. 8 .

[4] D.P. Ausubel, H. Hanesian, J.D. Novak, Educational psychology: A cognitive view, 1968.

[5] J.R. McClure, B. Sonak, H.K. Suen, Concept map assessment of classroom learning: Reliability, validity, and logistical practicality. Journal of Research in Science Teaching: The Official Journal of the National Association for Research in Science Teaching, 1999, Vol. 36(4), pp. 475-492.

[6] C.C. Ayala, M.A. Ruiz-Primo, R.J. Shavelson, J. Vanides, Y. Yin, Comparison of two conceptmapping techniques: Implications for scoring, interpretation, and use. Journal of Research in Science Teaching: The Official Journal of the National Association for Research in Science Teaching, 2005, Vol. 42(2), pp. 166-184.

[7] M.A. Ruiz-Primo, S.E. Schultz, R.J. Shavelson, Concept map-based assessment in science: Two 
exploratory studies. Center for Research on Evaluation, Standards, and Student Testing, Graduate School of Education \& Information Studies, University of California, Los Angeles, 1997.

[8] A.J. Cañas, J.D. Novak, The theory underlying concept maps and how to construct and use them, 2008.

[9] P. Susongko, Validation of science achievement test with the rasch model. Jurnal Pendidikan IPA Indonesia, 2016, vol. 5(2), pp. 268-277.

[10] S. Saptono, Strategi belajar mengajar biologi. Semarang: Universitas Negeri Semarang, 2003.

[11] G.L. Canivez, J.M. Nelson, Examination of the structural, convergent, and incremental validity of the Reynolds Intellectual Assessment Scales (RIAS) with a clinical sample. Psychological Assessment, 2012, vol. 24(1), p. 129.

[12] D. Hartati, Implementasi Berpikir Positif Dalam Buku "Terapi Berpikir Positif Karya Dr. Ibrahim Elfiky" Dalam Bimbingan Konseling Berkebutuhan Khusus. Al-Isyraq: Jurnal Bimbingan, Penyuluhan, dan Konseling Islam, 2018, Vol. 1(2).

[13] I. Cimermanová, Z. Straková, Critical thinking development-A necessary step in higher education transformation towards sustainability. Sustainability, 2018, Vol. 10(10), 3366.

[14] T.E. Tochilkina, E.V. Vasilieva, Design thinking and process transformation: Synergy of these approaches. In CEUR Workshop Proc, 2020, Vol. 2570, pp. 1-9.

[15] J. Greene, J. Millman, The specification and development of tests of achievement and ability, 1989.

[16] M.A. Ruiz-Primo, Examining concept maps as an assessment tool, 2004. 